\title{
Development of High Fidelity, Fuel-Like Thermal Simulators for Non-Nuclear Testing
}

\author{
Shannon M. Bragg-Sitton ${ }^{1}$, Ricky Dickens ${ }^{1}$, David Dixon ${ }^{2,3}$, Richard Kapernick ${ }^{2}$, \\ Mike Adams ${ }^{1}$, Joe Davis ${ }^{1}$ \\ 'NASA Marshall Space Flight Center, Nuclear Systems Branch / ER24, MSFC, AL 35812 \\ ${ }^{2}$ Los Alamos National Laboratory, Decision Applications Division, Los Alamos, NM 87545 \\ ${ }^{3}$ North Carolina State University, Raleigh, NC \\ 256.544.6272,Shannon.M.Bragg-Sitton@nasa.gov
}

\begin{abstract}
Non-nuclear testing can be a valuable tool in the development of a space nuclear power or propulsion system. In a non-nuclear test bed, electric heaters are used to simulate the heat from nuclear fuel. Work at the NASA Marshall Space Flight Center seeks to develop high fidelity thermal simulators that not only match the static power profile that would be observed in an operating, fueled nuclear reactor, but also match the dynamic fuel pin performance during feasible transients. Comparison between the fuel pins and thermal simulators is made at the outer fuel clad surface, which corresponds to the outer sheath surface in the thermal simulator. The thermal simulators that are currently being developed are designed to meet the geometric and power requirements of a proposed surface power reactor design, accommodate testing of various axial power profiles, and incorporate imbedded instrumentation. Static and dynamic fuel pin performances for a proposed reactor design have been determined using SINDA/FLUINT thermal analysis software, and initial comparison has been made between the expected nuclear performance and the performance of conceptual thermal simulator designs. Through a series of iterative analysis, a conceptual high fidelity design will be developed, followed by engineering design, fabrication, and testing to validate the overall design process. Although the resulting thermal simulator will be designed for a specific reactor concept, establishing this rigorous design process will assist in streamlining the thermal simulator development for other reactor concepts. This paper presents the current status of high fidelity thermal simulator design relative to a SNAP derivative reactor design that could be applied for Lunar surface power.
\end{abstract}

Keywords: non-nuclear testing; thermal simulators; electrical heaters.

PACS: 28.41.Ak.

\section{BACKGROUND}

At the NASA MSFC Early Flight Fission Test Facility (EFF-TF) electric heaters are used to simulate the heat from nuclear fuel to test space fission power and propulsion systems. To allow early utilization, nuclear system designs must be relatively simple, easy to fabricate, and easy to test using non-nuclear heaters to closely mimic heat from fission. In this test strategy, specialized electric heaters are used to simulate the heat from nuclear fuel, allowing one to develop an understanding of individual components and integrated system operation without the cost, time and safety concerns associated with nuclear testing. Electric heaters have been used for this purpose in numerous terrestrial and space reactor test and development programs (e.g., Casal, 1980; Ott and McCulloch, 2004a; Suriano, 1993; Maslo and Hyer, 1976; Balashov et al., 2002). The thermal simulators (heaters) developed at the EFF-TF have been applied in a variety of space reactor concepts for power or propulsion applications (Bragg-Sitton and Forsbacka, 2004; Godfroy, Kapernick and Bragg-Sitton, 2004; Vandyke et al., 2003; Vandyke, Martin and Houts, 2003). To accurately represent the fuel, the simulators should be capable of matching the overall properties of the nuclear fuel rather than simply matching the fuel temperatures. This includes matching thermal stresses in the pin, effective pin conductivities, total core power, and core power profile (axial and radial) during both static and dynamic test conditions. 
Initial simulator requirements were driven by past space reactor work and bounding parameters were chosen to be as challenging as possible. Basic design requirements included: fuel pin linear heat rate $\sim 100 \mathrm{~W} / \mathrm{cm}$, fuel power density $\sim 100 \mathrm{~W} / \mathrm{cm}^{3}$, and average axial pin power peaking of 1.33 (cosine distribution). Concepts considered as many as 200-500 pins per reactor core, with each pin providing 0.5 to $6 \mathrm{~kW}$ power as a function of the core design; considered pin diameters range from 0.65 to $2.4 \mathrm{~cm}$. Operational requirements for the thermal simulators incorporate desired lifetime (10,000+ hours), thermal cycling $(200+$ cycles), and test environment. EFF-TF thermal simulators were required to operate in a vacuum $\left(\sim 10^{-3}\right.$ to $10^{-6}$ torr) or in a low pressure high-purity gas (e.g. $\mathrm{He}, \mathrm{CO}_{2}, \mathrm{Ar}, \mathrm{etc}$.) environment. To simplify insertion in each reactor test article and to minimize the impact of the simulators on the ability to achieve a prototypic non-nuclear test article, a single-ended heater design was selected. Additionally, simulators employed in reactor test articles must be electrically isolated from the core to prevent shorting and should be physically isolated to prevent test article contamination by the simulators (e.g. due to sublimation, outgassing, etc.).

Thermal simulators previously designed and tested at the EFF-TF were constructed to meet the individual pin power levels and to roughly emulate the axial power distribution of specific reactor designs (Bragg-Sitton and Dickens, 2006). Early testing utilized graphite rod heaters encased in a stainless steel sheath; additional refractory metal wire wrapped heater element designs have also been fabricated and tested for use with reactor concepts that require refractory materials. Axial power variation was accomplished by varying the graphite element diameter (and, hence, varying its resistance) to produce an approximate cosine distribution axially, or by cutting the mandrel for wire wrapped elements with a varying pitch, as specified in an equation provided by reactor designers, to match the fuel element power distribution. Element testing has been conducted for rhenium, tantalum, tungsten, molybdenum, hafnium and niobium wires. Previous testing demonstrated that graphite rod heater elements are significantly more robust than any of the tested refractory wire elements, allowing instantaneous power changes without affecting the integrity of the heater. However, compatibility of graphite with some proposed core materials led to the investigation of refractory materials for thermal simulators. Advanced graphite elements are currently being investigated for use in lower power, stainless steel reactor cores for surface power application and are employed in the designs discussed in this paper.

Thermal simulators have been tested in single element and full core array configurations (Vandyke, Martin and Houts, 2003; Vandyke et al., 2003). Power is provided to each core test article via an automated 32-zone power and control system. Employing multiple independent power zones allows simulation of the expected radial power profile of the tested reactor design, under nominal or off-nominal conditions. Single element tests incorporate thermocouple temperature measurements on the element sheath, and full core array tests have previously incorporated temperature measurements in the interstitial regions between elements (Bragg-Sitton and Forsbacka, 2004). Fully instrumented thermal simulators are currently under development, as will be discussed in this paper.

\section{DESIGN PROCESS}

A detailed design process has been adopted for thermal simulator development and testing; this process will be referred to as "Track I" design. This procedure will result in the development of a high fidelity thermal simulator design that will be capable of meeting the static and dynamic performance properties of nuclear fuel in a specific reactor design.

The design process is iterative in nature and is based on detailed design requirements from reactor designers at Los Alamos National Laboratory. A variety of materials build-up options are considered in the "Concept Development" loop to achieve a concept design capable of meeting the ideal performance characteristics set forth by the expected nuclear fuel performance, determined via detailed thermal analysis. The heater element resistance, given by Eq. (1), is used to determine the potential power that can be provided by a single heater element using Ohm's Law, $P=I^{2} R$. (Note: All variables are defined in the Nomenclature section at the end of this paper.)

$$
R=\rho_{R} \frac{l}{A}
$$

For concentric cylinders, the radial heat transfer from the center to the outer surface is governed by the gap conductance $G_{g a p}$ (Eq. 2) and the gap radiative conductance $G_{\text {rad, gap }}$ (Eq. 3). 


$$
\begin{gathered}
G_{g a p}=\frac{2 \pi L k}{\ln \left(\frac{D_{\text {outer }}}{D_{\text {immer }}}\right)}, \\
G_{\text {rad }, \text { gap }}=\pi D_{\text {imer }} \sigma E=\pi D_{\text {imer }} \sigma\left(\frac{1}{\varepsilon_{\text {inner }}}+\frac{1-\varepsilon_{\text {outer }}}{\varepsilon_{\text {outer }}}\left(\frac{D_{\text {inner }}}{D_{\text {outer }}}\right)\right)^{-1} .
\end{gathered}
$$

These conductances are then used to determine temperatures by solving a heat balance equation in the radial direction, where $\mathrm{Q}$ is the heat transferred between the specified concentric surfaces.

$$
Q=G_{\text {gap }}\left(T_{\text {imner }}-T_{\text {outer }}\right)+G_{\text {rad }, \text { gap }}\left(T_{\text {inner }}{ }^{4}-T_{\text {outer }}{ }^{4}\right) \text {. }
$$

These surface temperatures are tied to the outer coolant boundary condition. The coolant temperature, $\mathrm{T}_{\text {bulk }}(\mathrm{z})$, increases as it flows through the reactor core as a result of the heat deposited by the fuel pin or electric simulator; this is described by the macroscopic energy equation. Given steady state conditions, the energy balance at the interface between the coolant and the fuel element (clad) or thermal simulator, this yields:

$$
T_{b u l k}(z)=T_{i n}+\frac{\int q_{o}^{\prime} f(z) d z}{\dot{m} C_{p}} .
$$

Analyses of fuel pin and simulator performance are conducted using fixed coolant inlet temperature and flow rate.

The concept design then enters the "Advanced Design" stage, in which materials availability and manufacturing feasibility is taken into greater consideration in developing detailed engineering designs. If the concept design is found to be infeasible for hardware manufacture, the design must return to the concept development loop and recommendations of the engineering design team participants must be taken into account to modify the concept design. The final advanced design that results from this process will strike a balance between meeting the performance criteria set forth by the nuclear design and the feasibility of manufacture at a reasonable cost and within a reasonable time frame. When the advanced simulator design is complete, a parallel process of calorimeter design and development will be initiated to allow for simulator testing with appropriate heat removal. All element testing will be performed inside a vacuum chamber, which can be backfilled with helium gas to assist in heat removal from the bare element in initial checkout testing or to improve thermal coupling between the heater element and the calorimeter. Thermal simulator testing with active heat removal may also be conducted for a single flow cell test article to study the performance given dynamic heat removal with the appropriate boundary conditions (e.g. in the presence of flowing $\mathrm{NaK}$ coolant at the outer boundary of the simulator sheath).

The Track I thermal simulator design is based on a potential Fission Surface Power Primary Test Circuit (FSP-PTC) reactor design. Currently, the simulator design is based on a derivative of the Systems for Nuclear Auxiliary Power (SNAP) reactor designs (Angelo and Buden, 1985) that could be used on the Lunar surface. This design basis will be referred to as the SNAPf3 concept. The SNAPf3 is a thermal spectrum reactor designed to operate at $98 \mathrm{kWt}(25$ $\mathrm{kWe}$ ) with reactor cooling provided by pumped liquid metal (NaK). The SNAPf3 incorporates $114 \mathrm{UZrH}$ fuel pins, yielding an average pin power of $0.86 \mathrm{kWt}$; the peak-to-average power ratio of 1.24 yields a maximum pin power of $1.07 \mathrm{kWt}$. Prior to receiving detailed requirements regarding the desired thermal simulator performance under static and transient conditions for the SNAPf3 concept (the first step in the iterative design process), a design and fabrication feasibility study was initiated to allow hardware work to progress. The primary objective of this exercise was to scope out potentially feasible design concepts and to work through any potential manufacturing issues given the geometry and total power requirements for a SNAPf3 fuel pin. The process flow for this simulator design is referred to as "Track II." Note that the primary difference between this and the Track I process flow is that the nuclear design is used only to produce a rough conceptual design for the thermal simulator without going through the detailed performance optimization required by the Track I process flow. The Track II thermal simulator design 
will be used as a starting point for the iterative Track I conceptual design while answering the hardware feasibility questions. Lessons learned under the Track II development will feed into the Track I design.

\section{CURRENT HARDWARE DEVELOPMENT}

Key thermal simulator features that should be incorporated with advanced simulator design have been identified. All advanced thermal simulators should demonstrate:

1. Ability to install instrumentation (e.g. thermocouples or fiber optics) to fully characterize simulator performance and to provide key input data to dynamic system testing of a full core array.

2. Ability to swap out thermal simulators in the core assembly between tests without draining system coolant $(\mathrm{NaK})$; this will allow testing of various axial power profiles without significant core overhaul.

3. Ability to incorporate a "necked down" region of the thermal simulator assembly; a reduced diameter sheath through the $\mathrm{NaK}$ flow plenum attempts to minimize impact of the simulator on the flow, improving the similarity between the non-nuclear and nuclear performance.

\section{Instrumentation Approach and Motivation for Selected Design Features}

The advanced thermal simulator design will incorporate multiple thermocouples (TCs) at several axial and radial locations. This instrumentation will provide more accurate characterization of the thermal simulator performance than in previous designs and will allow verification of the actual performance relative to the desired performance prescribed by the nuclear design. The initial advanced thermal simulators produced in this effort will match the desired overall geometry prescribed by the SNAPf3 reactor design but will not seek to match static and dynamic fuel pin performance; the latter will be addressed in the Track I development path. Computational fluid dynamic (CFD) analysis will be required to determine how much variation is expected in the temperature contour around a single heated element; this information will assist in determining appropriate thermocouple locations around the circumference of the thermal simulator.

A thermal simulator design that incorporates a necked down region was pursued under the Track II design process in accordance with requirements 2 and 3 above. This design does not attempt to incorporate replaceable TCs should some fail during test; the primary purpose in designing for heater swap-out is to allow testing of various power profiles within the same overall core configuration without requiring that $\mathrm{NaK}$ be flushed from the system. Because it is anticipated that the simulator sheaths will be welded to the vessel to ensure reliable seals, it will not be possible to swap out the full simulator assembly (including sheath and imbedded TCs) even if liquid metal is flushed from the core.

The Track II simulators will address fabrication issues associated with a simulator design having a reduced diameter sheath at one end and requiring instrumentation wiring to be fed along the full simulator length. In the nuclear system, the fuel pin structural supports will be located at the end of the fueled core height and the fuel pin clad will not extend through the flow plenum. In the non-nuclear system, extension of the thermal simulator sheaths through the flow plenum is necessary to allow power to be supplied to the heater elements, potentially affecting the flow dynamics of the $\mathrm{NaK}$ coolant in the region. A reduced diameter sheath in the plenum region seeks to minimize impact of the simulator on the flow, improving the similarity between the non-nuclear and nuclear performance. The potential impact of the thermal simulators on the flow performance must be assessed by CFD analysis and verified through testing in a flowing $\mathrm{NaK}$ environment, either on the full core or on a partial core array (e.g. single flow cell test article or 19 element core array); this will be completed as a part of the Track I development path.

The initial advanced thermal simulator test unit will be tested for electrical performance in a vacuum chamber, will be tested with active heat removal inside a specially designed calorimeter, and will then be tested in a flowing NaK environment as a part of a single flow cell geometric configuration that represents a "module" in the overall FSPPTC design. Although the initial advanced thermal simulators will be tested with a single heater core, the design will allow for that heater core to be modified in future testing to simulate power profiles at various stages in the reactor life or to simulate failure scenarios. 


\section{Initial Track II Simulator Design}

The thermal simulator design developed under the Track II design path is used as a baseline for initiating the Track I conceptual design. This design adheres to the overall geometry of the SNAPf3 reactor design concept proposed for the FSP-PTC and is capable of meeting the individual pin power requirements previously discussed based on calculations of the element resistance per Eq. (1); the resulting temperatures radially across the pin are then calculated using the heat balance equation (Eq. 4).

The heater element for the Track II simulator is constructed from AXZ-5Q graphite from POCO Graphite, as used in previous graphite heater elements tested at the EFF-TF. The heater element has a length of $43.5 \mathrm{~cm}\left(17.125^{\prime \prime}\right)$ and a constant outer diameter of $0.874 \mathrm{~cm}\left(0.344^{\prime \prime}\right)$. Future testing may consider shaped graphite elements to allow testing with various axial power profiles, as predicted from reactor design calculations. The graphite element is cut into two halves, connected by graphite at the non-power feed end. A flat piece of insulating material, referred to as a lead spacer, is inserted into this gap to prevent electrical contact. A center bore hole is cut through a portion of the spacer to allow a TC to be inserted down the center of the element; the TC junction will be located at the axial center of the heated region of the simulator.

The simulator sheath will be constructed from 316 stainless steel (SS316). As discussed above, the outer diameter of the sheath is reduced from $2.36 \mathrm{~cm}\left(0.930^{\prime \prime}\right)$ to $1.27 \mathrm{~cm}\left(0.500^{\prime \prime}\right)$ through the NaK flow plenum, where the reduced inner diameter of $1.09 \mathrm{~cm}\left(0.430^{\prime \prime}\right)$ is the minimum required for heater installation/removal. Previous EFFTF thermal simulator designs maintained a constant cross section along their full length. A heat pipe cooled reactor design does not require a pressure vessel and does not incorporate a flow plenum, such that the requirement for power feedthroughs for non-nuclear testing does not introduce any new variables relative to the nuclear design (Bragg-Sitton and Forsbacka, 2004; Vandyke, Martin and Houts, 2003). In a gas cooled reactor design, the copper power leads can be in direct contact with the cooling media, such that the sheath is not required to penetrate the full length of the flow plenum (Godfroy, Kapernick and Bragg-Sitton, 2004). However, because liquid metal is electrically conductive, the power leads cannot come in contact with the cooling media. This requires the sheath to penetrate the full length of the flow plenum, such that the power leads can be connected external to the core. It is expected that these penetrations will affect the liquid metal flow dynamics to some extent, but CFD analysis must be performed to quantify this affect. To minimize the potential variables between the non-nuclear test hardware and the nuclear fueled core, the diameter of the sheath was reduced as much as possible through the plenum region. An assembly drawing of the proposed simulator sheath is shown in Fig. 1. After the bottle neck portion is welded to the straight section of the sheath, 6 grooves $\left(0.020^{\prime \prime}\right.$ depth) are cut along the OD of the sheath to allow for thermocouple placement.

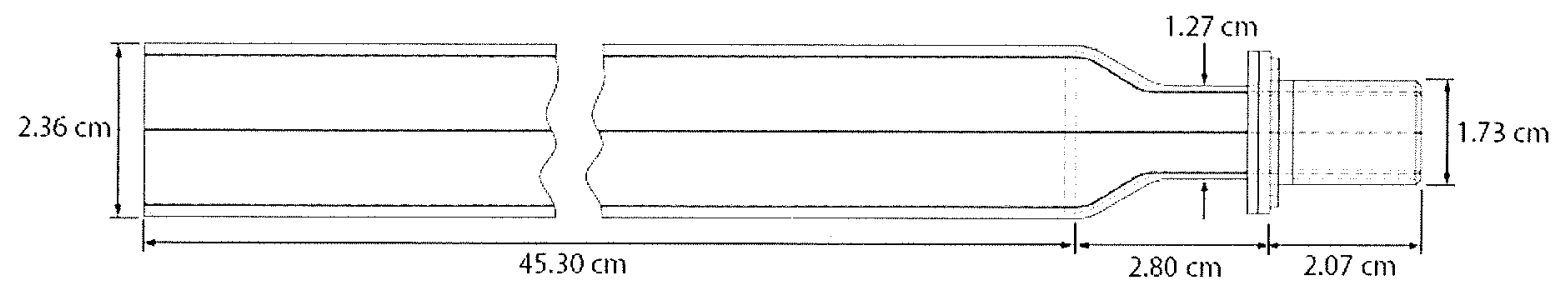

FIGURE 1. Stainless Steel Simulator Sheath with Neck Down Region, Track II Engineering Design.

The Track II development path will test multiple insulator materials and configurations. Variations in material composition and packing density (e.g. solid versus powder fill) provide variations in the thermal conductivity and the heat capacity of the insulator, both of which affect how quickly the heat can be transferred from the central heater element to the outer sheath. Vacuum gaps provide a barrier for heat transfer (allowing for only radiative heat transfer); therefore, the simulator is designed to minimize the number of gaps between the heater, insulator and sheath. During testing in a helium environment, any gaps (necessary for fabrication tolerances and assembly) are filled with helium to again maximize the heat transfer radially across the simulator. TCs will be imbedded in the outer diameter of the insulator preforms at the same axial locations as the sheath TCs. Each subsequent TC will be in a location that is rotated azimuthally from the adjacent $\mathrm{TC}$. 
All proposed simulator designs utilize a solid alumina insulator in the necked down region. Because this is not part of the heated length, the radial heat transfer in this region is not significant in providing a test that is representative of the fueled reactor equivalent. However, the insulator component is required to allow TC leads to be fed in/out of the thermal simulator. Alumina was selected for this region due to its relative low cost and easy machinability given the complexity of the piece. Alumina also provides sufficient strength to minimize potential breakage in the necked down region during handling required to insert and connect thermocouples and to connect power leads.

The first insulator design that will be tested considers solid insulating pieces along the straight portion of the thermal simulator. Initial tests will use solid alumina $\left(\mathrm{Al}_{2} \mathrm{O}_{3}\right)$, but boron nitride (BN) and aluminum nitride (AIN) are also potential options in the final simulator design. The insulator preform has an outer diameter of $2.08 \mathrm{~cm}\left(0.820^{\prime \prime}\right)$ and a wall thickness of $0.59 \mathrm{~cm}\left(0.233^{\prime \prime}\right)$. A small allowance between the outer diameter of the insulator and the inner diameter of the sheath is allowed for assembly purposes. During testing this space is either a vacuum gap or is filled by helium gas at $\sim 50$ torr. Six notches are cut along the length of the insulator at the outer diameter for instrumentation placement. These are spaced symmetrically around the part, such that each is at an angle of $60^{\circ}$ relative to its neighbor, as shown in Fig. 2. These notches allow placement of TCs at various axial locations; they are mimicked through the necked down region, which narrows from an outer diameter of $2.08 \mathrm{~cm}$ to $1.07 \mathrm{~cm}$ $\left(0.820^{\prime \prime}\right.$ to $\left.0.420^{\prime \prime}\right)$, to allow TCs to be fed outside the thermal simulator.

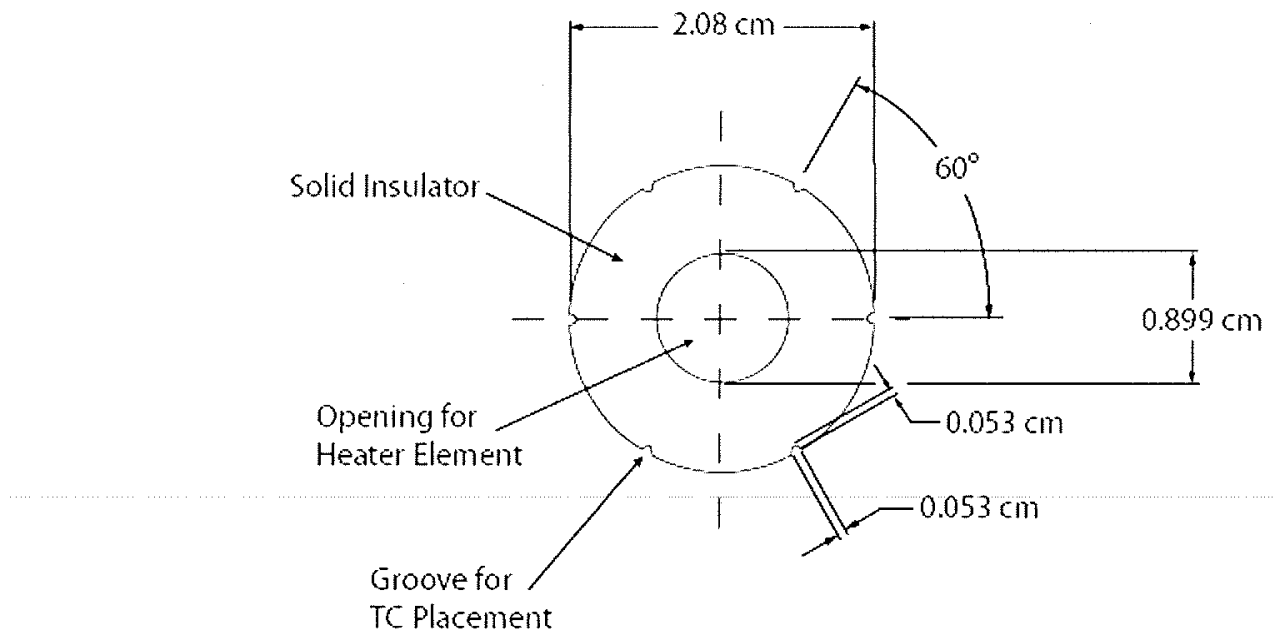

FIGURE 2. Cross Section of the Full Insulator Preform Showing Notches for TC Placement.

The second insulator design is based on that shown in Fig. 2, but adopts a reduced outer diameter of $1.83 \mathrm{~cm}$ $\left(0.720^{\prime \prime}\right)$ along tho ntraight section. This configuration increases the gap between the solid insulator and the inner diameter of the sneath, allowing that space to be packed with a fine insulating powder. Assuming that good packing can be achieved, this will allow an improved conduction path from the insulator to the sheath because no gas gap will be required. Additionally, various powders can be tested with the same solid insulator preform, allowing a greater database of information to be collected during this initial advanced simulator testing. Powders that will be tested include: $\mathrm{Al}_{2} \mathrm{O}_{3}, \mathrm{BN}, \mathrm{AIN}$, natural diamond, and $\mathrm{CVD}$ diamond. The reduced diameter of the insulator does, however, require that the thermocouples placed along the outer diameter of the preform be moved from their approximate location at the sheath ID to the $1.83 \mathrm{~cm}\left(0.720^{\prime \prime}\right)$ outer diameter of the solid preform. Because additional temperature measurements will be taken at the outer diameter of the sheath this should not significantly affect the ability to obtain the desired data. Thermal analysis will be used to further assess simulator performance in each configuration.

The Track II simulator design will be used as a baseline design to initiate computational analysis that will direct the conceptual design of the Track I simulator. Both the solid insulator and solid plus powder insulator designs will be considered in the initial conceptual design phase, as discussed in the next section. 


\section{TRACK I DEVELOPMENT: COMPUTATIONAL ANALYSIS}

The Track I thermal simulator development path is focused on designing simulators that match the performance of nuclear fuel elements in a specific reactor design. Comparison between the thermal simulator and the modeled nuclear fuel element will be made at the clad outer diameter, ensuring that the simulator matches the anticipated clad surface temperature under nominal static operation (e.g. at a specified nominal power level) and during an anticipated transient operation (e.g. $\pm 25 \%$ power variation). The thermal simulator should be capable of matching the clad surface temperature before and after the power transient and should, ideally, match the anticipated response time of the fueled system. Variation of the thermal conductivity and thermal inertia of the simulators will be accomplished by varying the material composition and thicknesses between the central heating element and the sheath used to encase the simulator. Initial investigations will use a central graphite heater element and a stainless steel sheath as a baseline with various insulating materials considered between the heater and sheath, layered in such a way as to mimic the expected fuel pin performance. Selected properties of potential insulating materials are summarized in Table 1.

TABLE 1. Representative Properties of Proposed Insulating Materials.

\begin{tabular}{|c|c|c|c|}
\hline Material & $\begin{array}{l}\text { Density } \\
\left(\mathrm{g} / \mathrm{cm}^{3}\right)\end{array}$ & $\begin{array}{c}\text { Thermal Conductivity } \\
\text { @ } 1000 \mathrm{~K} \\
\text { (W/cm-K) }\end{array}$ & $\begin{array}{c}\text { Specific Heat } \\
\text { @ } 1000 \mathrm{~K} \\
(\mathrm{~J} / \mathrm{kg}-\mathrm{K})\end{array}$ \\
\hline Alumina $\left(\mathrm{Al}_{2} \mathrm{O}_{3}\right)$ & 3.9 & 0.07 & 1255 \\
\hline Alumina Nitride (AIN) & 3.2 & 0.48 & 1230 \\
\hline Boron Nitride (BN) & $2.25 /$ tap: $0.5^{\S}$ & 0.30 & 1790 \\
\hline Natural Diamond & 3.51 & -20@293 K & 1800 \\
\hline Synthetic CVD Diamond & 3.51 & $\sim 12 @ 485 \mathrm{~K}$ & $\sim 1300 @ 573 \mathrm{~K}$ \\
\hline
\end{tabular}

**Note: Properties are based on solid materials; density reduction and conductivity reduction must be estimated in modeling powdered materials and should be verified experimentally. Source: NIST Standard Reference Database \#30, Structural Ceramics Database, April 2003, http://www.ceramics.nist.gov/srd/scd/scdquery.htm. ${ }^{\S}$ Value provided by ESPI for powdered BN purchased (2N5 purity, 325 mesh); T.A.P. density reported as $0.5 \mathrm{~g} / \mathrm{cm}^{3}$.

Analysis of the static and dynamic performance of a SNAPf3 fuel pin was necessary before initiating the design of a highly accurate thermal simulator capable of matching expected fuel pin performance under nominal static conditions and during potential transients. This analysis was performed using SINDA/FLUINT thermal analysis software on a model of the fuel pin. Transients of interest might include modest $( \pm 25 \%)$ power variations, full shutdown, and variations on the secondary side of the system, including variations in the coolant mass flow rate or in the coolant inlet temperature. Plots of the expected static fuel pin performance are provided in Fig. 3.

Initial dynamic analysis at the axial center for the Track II simulator design is shown in Fig. 4. The figure shows the behavior of two potential simulator designs and the SNAPf3 fuel pin following shutdown from nominal operation $(98 \mathrm{kWt})$ at time zero, where the shutdown is the result of a control maneuver on the primary side. The plots correspond to the sheath temperature and the fuel pin clad temperature at the axial centerline for a nominal pin operating at $0.86 \mathrm{kWt}$ prior to shutdown. For the powder case, the simulator is fabricated using both solid and powdered alumina between the graphite heater and the stainless steel sheath. Properties of the powder were estimated from known solid properties (Table 1); powder density was assumed to be $85 \%$ solid density and the conductivity was reduced to $75 \%$ that of the solid material. Analysis of the corresponding axial profile is shown in Fig. 5. The model was run for two different power distributions in each simulator: a shaped power distribution based on the fuel element power distribution determined from MCNPX analysis of the SNAPf3 reactor design (this results in a common profile at time zero for the fuel and simulator elements) and a constant $Q_{c}$, corresponding to the power distribution in a constant diameter graphite heater element. During static operation, it is evident that a shaped power profile should be adopted in the simulator design in order to properly match the fuel pin performance. At one minute following shutdown the axial profile of the simulator that uses layers of solid and powdered alumina is very closely matched to the temperature profile on the fuel element clad, even for the constant $Q_{c}$ model. 


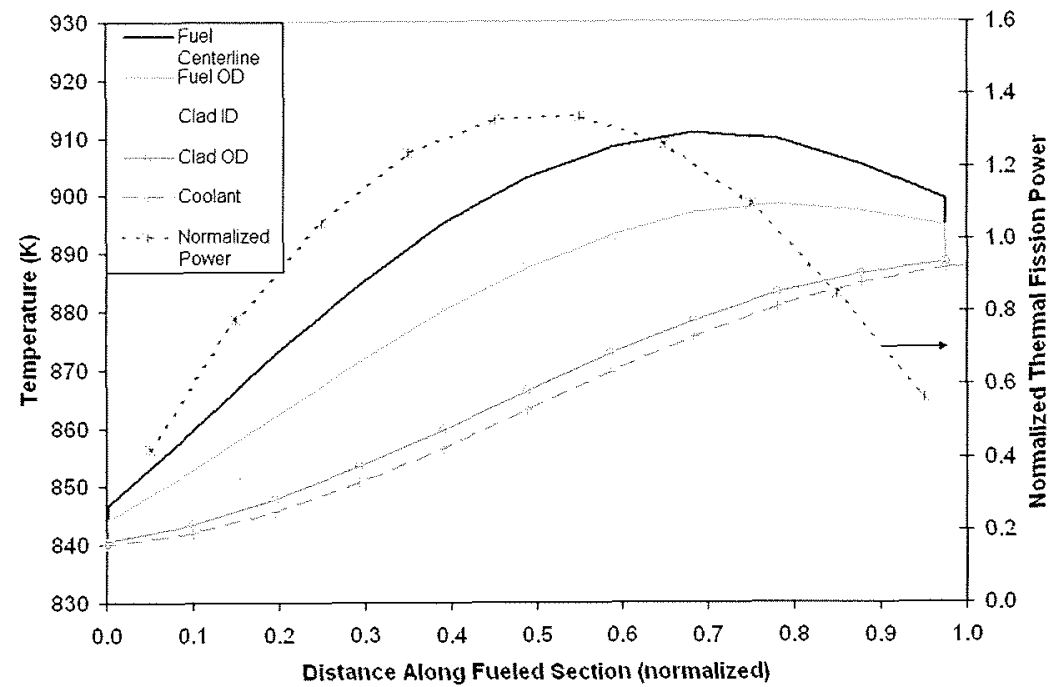

FIGURE 3. Axial Temperature Profile for a Conceptual SNAPf3 Fuel Pin for Reactor Operation at $98 \mathrm{kWt}(0.86 \mathrm{kWt} / \mathrm{pin}$, nominal) at the Beginning of Life (BOL).

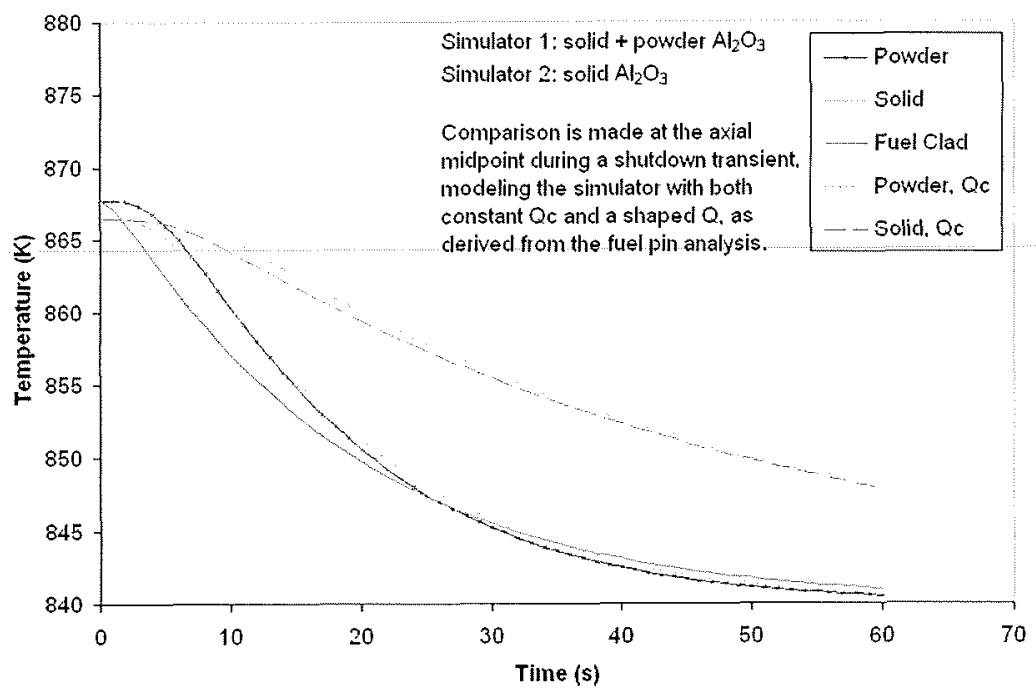

FIGURE 4. Thermal Simulator and Fuel Pin Temperature Following a Shutdown Transient from Steady State Operation at 98 $\mathrm{kWt}(0.86 \mathrm{kWt} / \mathrm{pin}$, nominal).

\section{CONCLUSIONS}

Non-nuclear testing can be a valuable tool in developing a nuclear system for space application within a reasonable time frame and budget. For these tests to provide an accurate representation of system operation, care must be taken to develop electrical thermal simulators that can mimic both static and dynamic behavior of the corresponding fueled element. The first steps have been taken to design and fabricate thermal simulators for a NaK cooled core design, and initial thermal analysis of proposed simulator designs shows significant promise in developing a simulator capable of mimicking dynamic fuel pin behavior. The initial $\mathrm{NaK}$ simulator designs (Track II) are 
currently being fabricated and testing is expected to commence in early FY07. Conceptual and engineering designs for the next generation (Track I) element will follow the initial testing and will be completed in CY07.

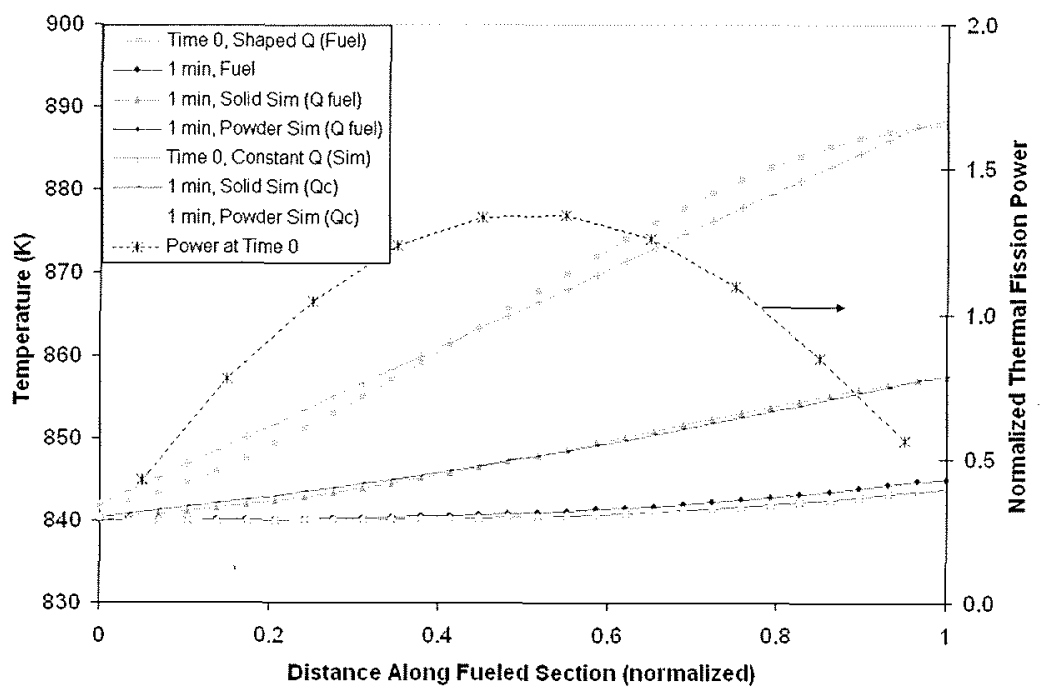

FIGURE 5. Thermal Simulator and Fuel Pin Clad Temperatures at Time Zero (nominal operation at $0.86 \mathrm{kWt} / \mathrm{pin}$ ) and One Minute Following a Shutdown Transient.

\section{NOMENCLATURE}

$\mathrm{L} \quad$ heater element length or gap length $(\mathrm{m})$

A heater element cross sectional area $\left(\mathrm{m}^{2}\right)$

I $\quad$ current (A)

$\rho_{R} \quad$ resistivity $(\Omega / \mathrm{m})$

$\mathrm{R} \quad$ resistance $(\Omega)$

P $\quad$ power $(\mathrm{W})$

$G_{g a p} \quad$ gap conductance $(\mathrm{W} / \mathrm{K})$

$G_{\text {rad, gap }}$ gap radiative conductance $\left(\mathrm{W} / \mathrm{K}^{4}\right)$

$\sigma \quad$ Boltzmann's constant $\left(5.67 \mathrm{E}-04 \mathrm{~W} / \mathrm{m}^{2} \mathrm{~K}^{4}\right)$

D diameter $(\mathrm{m})$ $\varepsilon \quad$ emissivity

$q_{\circ}^{\prime} \quad$ linear heat generation rate $(\mathrm{W} / \mathrm{m})$

$\mathrm{f}(\mathrm{z}) \cdots$ axial power distribution

$\mathrm{Q}$ total heat transferred radially (W)

$\mathrm{T} \quad$ temperature $(\mathrm{K})$

$\dot{m} \quad$ coolant mass flow rate $(\mathrm{kg} / \mathrm{s})$

$\mathrm{C}_{\mathrm{p}} \quad$ specific heat $(\mathrm{J} / \mathrm{kg}-\mathrm{K})$

$\mathrm{Z} \quad$ axial position along fuel/heater $(\mathrm{m})$

\section{ACKNOWLEDGMENTS}

NASA's Project Prometheus supported the work described within this report, in whole or part, as part of the program's technology development and evaluation activities. Any opinions expressed are those of the author(s) and do not necessarily reflect the views of Project Prometheus, NASA, or the Los Alamos National Laboratory.

\section{REFERENCES}

Angelo, J.A., and Buden, D., Space Nuclear Power, Orbit Book Company, Inc., Malabar, Florida, 1985, pp.159-175.

Balashov, S.M., Videneev, E.N., Veresov, A.V., Zorichev, V.V., Mal'tsev, B.K., and Smolin, V.N., "Electrical Heaters for Experimental Installations and Nuclear Power Stations," Thermal Engineering, 49(5), pp. 377-381 (2002).

Bragg-Sitton, S.M. and Dickens, R., "Thermal Simulator Development: Non-Nuclear Testing of Space Fission Systems," in proceedings of American Nuclear Society Winter Meeting, American Nuclear Society, La Grange Park, IL, 2006, paper 163833 . 
Bragg-Sitton, S.M. and Forsbacka, M., "Application of a Virtual Reactivity Feedback Control Loop in Non-Nuclear Testing of a Fast Spectrum Reactor," in proceedings of International Congress on Advanced Nuclear Power Plants (ICAPP-2004), American Nuclear Society, La Grange Park, IL, 2004, pp. 2259-2268.

Casal, V., "Design of High-Performance Fuel Pin Simulators for Thermodynamic Experiments with Nuclear Fuel Elements," Nuclear Technology, 47(1), 153-162 (1980).

Godfroy, T.J., Kapemick, R., and Bragg-Sitton, S.M., "Thermally Simulated 32kW Direct-Drive Gas-Cooled Reactor: Design, Assembly and Test," in proceedings of Space Technology and Applications International Forum (STAIF-2004), edited by M.S. El-Genk, AIP Conference Proceedings 699, Melville, New York, 2004, pp. 757-763.

Maslo, R.M., "Hybrid Simulation of a Nuclear Fuel \& Electric Heater Pin," in proceedings of the $8^{\text {th }}$ AICA Congress, edited by L. Dekker, North-Holland Publishing Company, Amsterdam, Netherlands, 1976, pp. 795-803.

Ott, L.J. and McCulloch, R, "Overview of Fuel Rod Simulator Usage at ORNL," Space Technologies and Applications International Forum (STAIF-2004), edited by M.S. El-Genk, AIP Conf Proc 699, Melville, New York, 2004, pp. 703-712.

Suriano, M., "TOPAZ-II Program: Initial US Demonstration Test Results on the TOPAZ-II Thermionic Space Nuclear Power System," in Proceedings of the $28^{\text {th }}$ Intersociety Energy Conversion Engineering Conference, American Chemical Society, Washington, D.C., 1993, pp. 855-861.

VanDyke, M. K., Houts, M.G., Godfroy, T.J., Dickens, R., Martin, J.J., Poston, D.I., Salvail, P., and Carter, R. (2003), "Test Facilities in Support of High Power Electric Propulsion Systems," in proceedings of Space Technology and Applications International Forum (STAIF-2003), edited by M.S. El-Genk, AIP Conference Proceedings 654, Melville, New York, 2003, pp. 451-456.

VanDyke, M.K., Martin, J.J., and Houts, M.G., Overview of Nonnuclear Testing of the Safe, Affordable 30-kW Fission Engine Including End-to-End Demonstrator Testing, NASA/TM-2003-212930, NASA Marshall Space Flight Center, Huntsville, $\mathrm{AL}, 2003$. 